\title{
Parent-activated medical emergency teams: a parent's perspective
}

\section{James Titcombe}

Correspondence to James Titcombe, Care Quality Commission, Unit 7b, Lakeland Business Park, Cumbria CA13 OQT, UK; james_titcombe@ yahoo.co.uk

JT is father of Joshua and a patient safety campaigner

Accepted 9 January 2015 Published Online First 29 January 2015

\section{SLinked}

http://dx.doi.org/10.1136/ bmjas-2014-003001

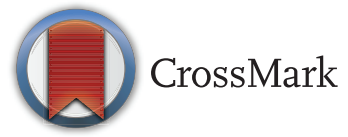

To cite: Titcombe J. BMJ Qual Saf 2015;24:182-183.
In 2008, I lost my baby son due to serious failures in his care at the hospital where he was born. Joshua's mother collapsed shortly after the birth and was treated with antibiotics and fluids. She soon made a full recovery, but Joshua, we were told by staff on the ward, was fine. In the $24 \mathrm{~h}$ following Joshua's birth, we were concerned about his condition. He was breathing quickly, seemed mucousy around his mouth and was struggling to maintain his body temperature. We raised repeated concerns with the midwifery staff that were looking after him. But each time, we were simply reassured he was ok. At $24 \mathrm{~h}$ of age, Joshua collapsed with overwhelming sepsis. (We later found out this was the same infection that had caused my wife's collapse shortly after the birth.)

Joshua's mother found him blue and bubbling around the mouth. At this point, he was finally taken to the special care baby unit. There, for the first time, he was seen by a doctor. He was ventilated and transferred to two different tertiary centres where he received intensive life support. Despite best efforts to save him, Joshua passed away just 9 days later as a consequence of damage to his lungs caused by the infection. We later learnt that Joshua would have almost certainly survived had he been treated with antibiotics earlier.

Coming to terms with Joshua's death has been difficult. I've often asked myself whether or not I could have done more to ensure Joshua was seen by a doctor sooner than he was. The truth, however, is that for patients, hospitals can be disempowering places. We enter them often with an acute awareness of how busy staff are, and we don't want to cause trouble or be disruptive. I knew that the midwifery staff caring for Joshua looked after newborn babies every day of their lives. Who was I to question the reassurances I was given?

Of course, this can be viewed from another angle. During the critical $24 \mathrm{~h}$ of Joshua's postnatal care, he was cared for by many different staff. Shifts changed, the transfer of information relied on handover processes. Staff were busy and saw Joshua in brief snaps shots of time. The one constant throughout these critical hours was my wife and I. Our observations of Joshua were made with a full understanding of the history and context of his birth and on a continuous basis.

As well as knowing their child better than anyone else, parents of children in hospital will always have this continuity and context on their side. This is something many hospitals now recognise and use to good effect. In the UK, Birmingham Children's Hospital, for example, now encourage parents to write down any observations or concerns about their child on a special form, which is then shared and discussed with staff. But could hospitals go a step further by enabling parents of children in hospital to summon emergency medical help directly?

The study by Brady $e t ~ a l^{1}$ in this issue of BMJ Quality and Safety suggests that, with the right support and education, parents with children admitted to hospital do make responsible use of parent-activated medical emergency teams. Staff in the study at Cincinnati Children's Hospital reported being reassured that there were not too many false alarms. The paper also found that some of the calls parents made did result in their child being admitted to the intensive care unit, suggesting that these interventions were clinically necessary and may not have otherwise occurred as quickly as they did.

These results are encouraging and suggest that parent-activated medical emergency teams are something that the Natiomal Health Service-and hospitals internationally—should consider trialling as a system that has a real potential to improve outcomes. While I don't know whether or not such a scheme would have made a difference in Joshua's case, this study suggests there are clearly potential benefits from families and professionals working together in this way. Further study 
and evaluation of family-activated medical emergency teams can, therefore, only be a good thing.

Competing interests None.

Provenance and peer review Not commissioned; internally peer reviewed.

\section{REFERENCE}

1 Brady PW, Zix J, Brilli R, et al. Developing and evaluating the success of a family activated medical emergency team: a quality improvement report. BMJ Qual Saf 2015;24:203-11. 